\title{
Staphylococcal Superantigen (TSST-1) Mutant Analysis Reveals that $T$ Cell Activation Is Required for Biological Effects in the Rabbit Including the Cytokine Storm
}

\author{
Norbert Stich ${ }^{1}$, Martina Waclavicek ${ }^{1}$, Nina Model ${ }^{1}$ and Martha M. Eibl ${ }^{1,2, *}$
}

1 Biomedizinische ForschungsgmbH Lazarettgasse 19/2, A-1090 Vienna, Austria; E-Mails: Norbert.Stich@biomed-research.at (N.S.);

Martina.Waclavicek@biomed-research.at (M.W.); Nina.Model@biomed-research.at (N.M.)

2 Immunology Outpatient Clinic, Schwarzspanierstrasse 15, A-1090 Vienna, Austria

* Author to whom correspondence should be addressed; E-Mail: martha.eibl@meduniwien.ac.at; Tel.: +43-1-4081091-11; Fax: +43-1-4081091-13.

Received: 2 August 2010; in revised form: 1 September 2010 / Accepted: 7 September 2010 / Published: 9 September 2010

\begin{abstract}
Staphylococcal superantigens (sAgs), such as toxic shock syndrome toxin 1 (TSST-1), induce massive cytokine production, which may result in toxic shock syndrome (TSS) and sepsis. Recently, we reported that in vitro studies in human peripheral blood mononuclear cells (PBMC) do not reflect the immunological situation of the host, because after exposure to superantigens (sAgs) in vivo, mononuclear cells (MNC) leave the circulation and migrate to organs, e.g., the spleen, liver and lung. Our experimental model of choice is the rabbit because it is comparable to humans in its sensitivity to sAg. T cell activation has been assessed by lymphocyte proliferation and IL-2 gene expression after in vivo challenge with TSST-1 and the mutant antigens; expression of the genes of proinflammatory cytokines were taken as indicators for the inflammatory reaction after the combined treatment with TSST-1 and LPS. The question as to whether the biological activities of TSST-1, e.g., lymphocyte extravasation, toxicity and increased sensitivity to LPS, are mediated by $\mathrm{T}$ cell activation or activation by MHC II-only, are unresolved and results are contradictory. We have addressed this question by studying these reactions in vivo, with two TSST-1 mutants: one mutated at the MHC binding site (G31R) with reduced $\mathrm{MHC}$ binding with residual activity still present, and the other at the $\mathrm{T}$ cell binding site (H135A) with no residual function detectable. Here, we report that the mutant G31R induced all the biological effects of the wild type sAg, while the mutant with non-functional
\end{abstract}


TCR binding did not retain any of the toxic effects, proving the pivotal role of $\mathrm{T}$ cells in this system.

Keywords: sepsis; inflammation; T cell involvement; superantigens; endotoxin

\section{Introduction}

Infections caused by Staphylococcus aureus (S. aureus) represent a health problem of increasing importance. Due to the growing prevalence of antibiotic resistance to these bacteria, new treatment options are urgently required to combat the disease. The severity of $S$. aureus sepsis is positively associated with staphylococcal toxins with properties of a superantigen (sAg) [1], e.g., TSST-1. In contrast to conventional antigens, sAg bind to major histocompatibility complex (MHC) II molecules outside the peptide-binding cleft and to the T cell receptor (TCR) variable $\beta$ chains (V $\beta$ ) on the T cell. The hypothesis has been put forward that cross-linking MHC II and the TCR induces inflammation characterized by a cytokine storm [2].

A cytokine storm followed by strong inflammation can cause widespread tissue damage and multiorgan failure [3,4]. The relatively weak in vivo and in vitro responses to sAg of mice compared with humans have been attributed to differences between mouse and human MHC II, thereby emphasizing the important role of MHC II [5,6].

Several attempts have been undertaken to detoxify TSST-1 by mutating either their TCR binding site (e.g., mutation of histidine 135 to alanine) [7] where the MHC binding site remains functional or the MHC II binding site (e.g., mutation of glycin 31 to arginine) with functional binding to TCR [8]. Results obtained with these mutants or from binding studies were contradictory in part. Some reports showed that inhibition of the interaction sAg-TCR could stop excessive inflammation [9,10], whereas others underlined the importance of MHC II binding [11]. Whether sAg-MHC II binding or TCR-sAg interaction is of decisive importance for activation of innate immunity has to be further clarified.

Schlievert et al. showed that streptococcal mutant sAgs lacking residues necessary for $\mathrm{T}$ cell activation still retained lethality in rabbit models [12]. These authors tested a series of single and double mutants showing that the ability of exotoxins to cause lethality and endotoxin enhancement does not require superantigenicity.

Dinges et al. showed that impairment of $\mathrm{T}$ cell function by cyclosporin protected rabbits against the lethality of toxic shock syndrome (TSS) [13]. In contrast, they showed that total body irradiation could not prevent TSS. However, they could not exclude the possibility that the results might have been skewed by a small number of radio-resistant $T$ cells.

Inflammation by LPS is strongly enhanced after priming with sAg [14]. The mechanism responsible for this sensitization is not well understood. It has been suggested that the upregulation of TLR4 by sAg might be responsible for the enhanced response to LPS [15] as TLR4 is the receptor for LPS and this mechanism of innate immunity might be responsible for the overwhelming inflammatory response that leads to tissue damage [16].

Kum et al. emphasized the importance of sAg/TCR interaction based on in vitro studies. They studied the temporal sequence of the cytokine expression pattern in human peripheral blood 
mononuclear cells (PBMC) after stimulation with wild type (wt) TSST-1, G31R and H135A. Using enzyme-linked immunoabsorbent assays (ELISAs), they showed that G31R induced a cytokine profile similar to that of wtTSST-1, while H135A showed complete absence of any cytokine secretion [9]. According to our knowledge, the biological effect of these mutants has never been studied in vivo.

SAgs are known to strongly increase sensitivity to LPS. Rabbits pretreated with even low doses of sAg die when exposed to low amounts of LPS [13]. The mechanism of this amplification is still poorly understood.

In our studies, using the mutant toxins G31R and H135A in vivo, we explored whether, in addition to MHC class II binding, T cell binding was mandatory for the sensitization for LPS.

Recently, applying quantitative real time PCR (qRT-PCR) and proliferation assays, we detected cell activation and strong induction of cytokine gene expression in the organs of rabbits soon after $\mathrm{sAg}$ administration. This activation could not be detected in the periphery [17]. Therefore, results obtained from the circulation do not accurately reflect the immunological state of the host.

Here we studied those biological effects of staphylococcal toxins (superantigens) of which the mechanisms of action are not well understood. We applied the mutants G31R and H135A and prove that $\mathrm{T}$ cell activation is mandatory for both $\mathrm{V} \beta$ unrestricted extravasation and for the sensitization for LPS.

\section{Results and Discussion}

2.1. G31R induces leukopenia, lymphopenia and monocytopenia in rabbits. In contrast, no effect on MNC subsets by H135A

Rabbits were studied in terms of their leukocyte and lymphocyte counts after administration of the TSST-1 mutants G31R and H135A. To compare the induced effects with the ones elicited by the wt protein, we used TSST-1 as a positive control. Negative control rabbits were only injected with PBS.

Prior to injection, WBC of rabbits $(n=20)$ tested were $6150 \pm 1905$ cells $/ \mu L(A V \pm S D)$. After application of G31R, the number of circulating leukocytes started to decline and decreased to $2171 \pm 378$ cells $/ \mu \mathrm{L}(\mathrm{AV} \pm \mathrm{SD}) 6 \mathrm{~h}$ after injection (Figure 1A). Thus, the counts of WBC were comparable to the levels reached $6 \mathrm{~h}$ after TSST-1 application $(1913 \pm 688$ cells $/ \mu \mathrm{L})$. The leukocytes within the circulation returned to baseline levels already $24 \mathrm{~h}$ after G31R injection which was slightly earlier than after TSST-1 application. No significant changes were observed in H135A-treated rabbits or in the controls (Figure 1A). Similar results were obtained with total lymphocyte counts after administration of G31R, TSST-1 versus H135A and PBS (Figure 1B).

Flow cytometric studies of different lymphocyte subsets revealed that the effects at G31R on the number of $\mathrm{CD}^{+}$and $\mathrm{CD}^{+} \mathrm{T}$ cells as well as $\mathrm{CD} 14^{+}$and $\mathrm{IgM}^{+}$cells within the circulation were comparable to the effects induced by TSST-1 (Figure 1C-1F). However, after G31R injection, cell counts of the studied subsets increased earlier as compared to TSST-1 suggesting a quantitative difference.

These results indicate extravasation of monocytes and lymphocytes by G31R comparable to TSST-1, while no effect was observed after injection of H135A under identical conditions (Figure 1A-1F). 
Figure 1. (a-f) Significant decrease of $\mathrm{CD}^{+}, \mathrm{CD}^{+}, \mathrm{IgM}^{+}$and $\mathrm{CD} 14^{+}$cells in the circulation of rabbits injected with G31R or TSST-1. No influence on cell counts of WBC and subsets after application of H135A. Rabbits were injected with either $100 \mu \mathrm{g}$ G31R $(\mathrm{n}=6)[\bullet]$ or $100 \mu \mathrm{g} \mathrm{H135A}(\mathrm{n}=6)$ [ $\square]$. The positive controls received TSST-1 $(\mathrm{n}=4)[\mathbf{\Delta}]$, PBS $(n=4)[X]$ and the negative controls received PBS $(n=4)[X]$. Prior to application, as well as $1 \mathrm{~h}, 2 \mathrm{~h}, 6 \mathrm{~h}, 24 \mathrm{~h}$ and $48 \mathrm{~h}$ after injection, the numbers of WBC (a) and total lymphocytes (b) were determined from venous blood of rabbits. The absolute numbers of the lymphocyte subsets (c) $\mathrm{CD}^{+}$, (d) $\mathrm{CD}^{+}$, (e) $\mathrm{IgM}^{+}$and (f) $\mathrm{CD}_{1} 4^{+}$were calculated from FACS analyses at the time points denoted, as described in Materials and Methods. Figures (c-f) show mean values \pm SD of the numbers of the indicated cell populations of 4 rabbits injected with G31R, and of 4 rabbits administered by H135A. Mean \pm SD of positive and negative control rabbits were calculated from 4 experiments.

(a).

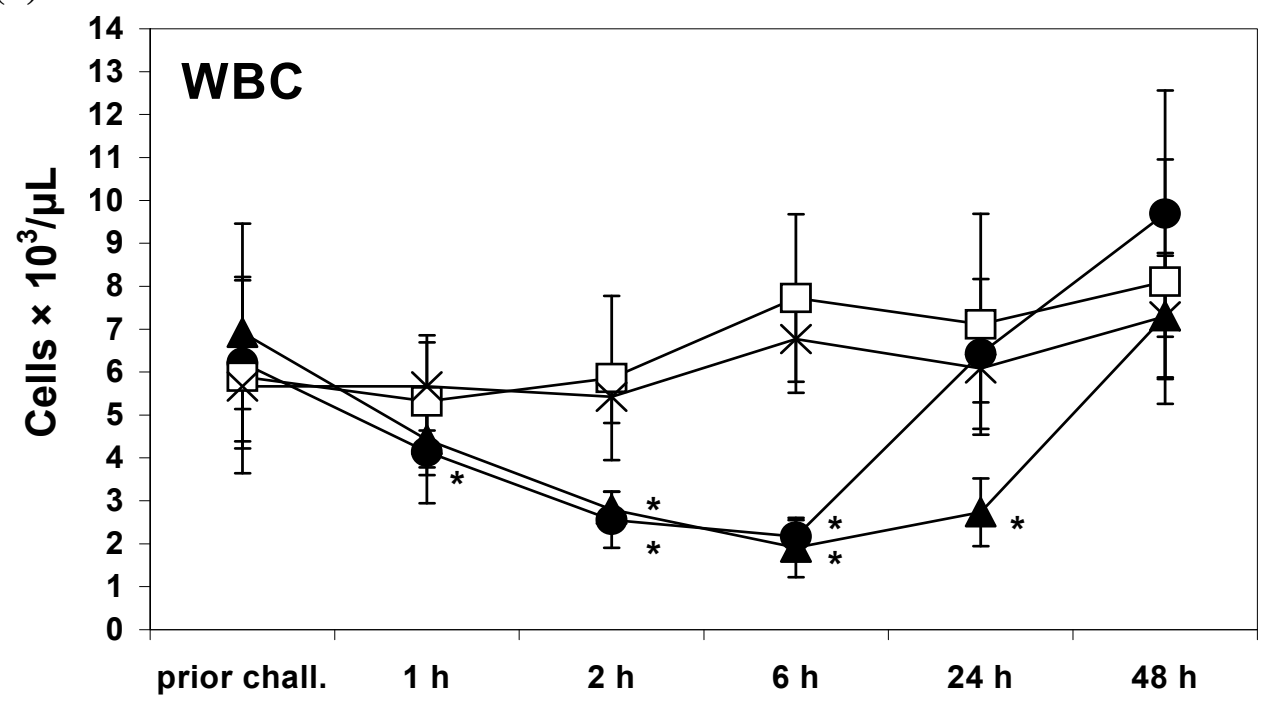

(b).

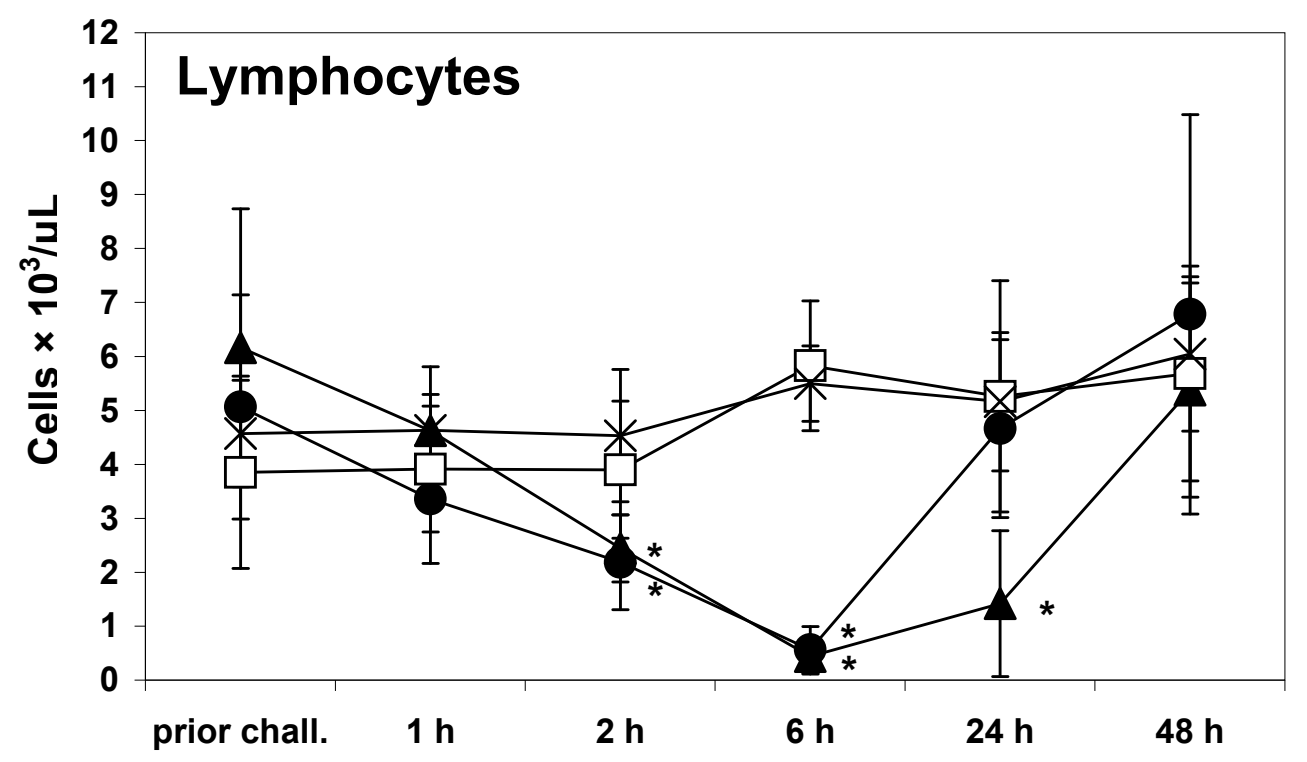


Figure 1. Cont.

(c).

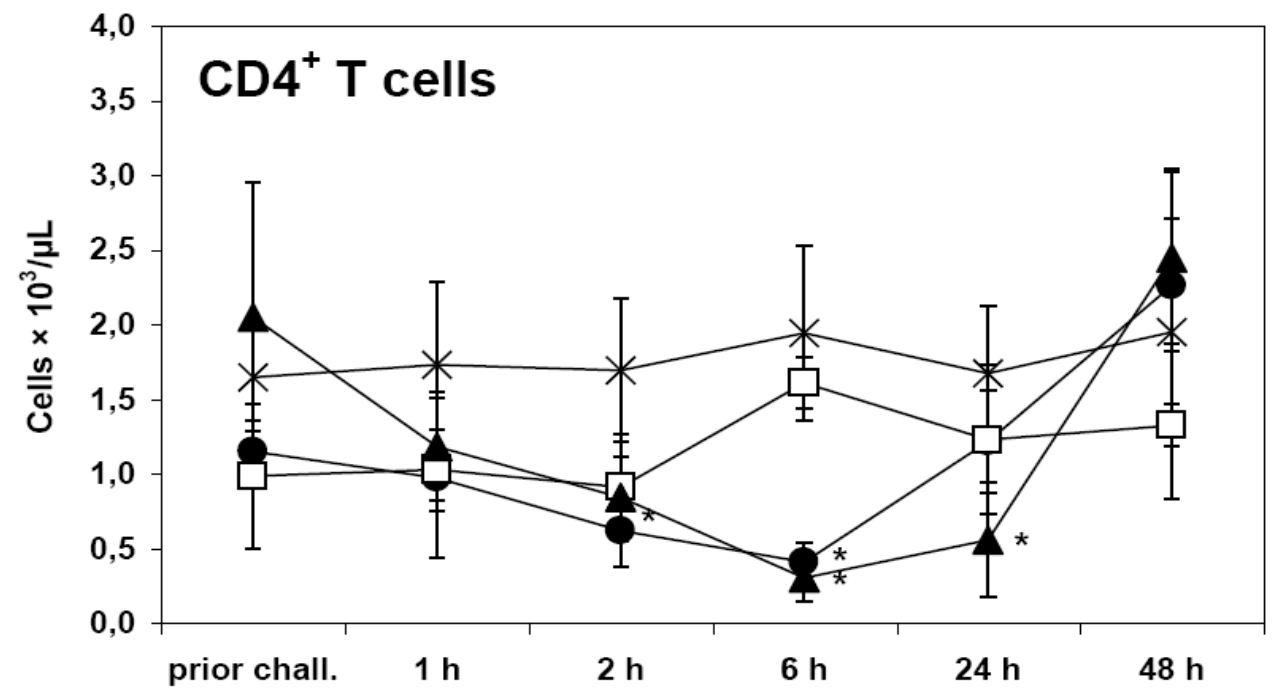

(d).

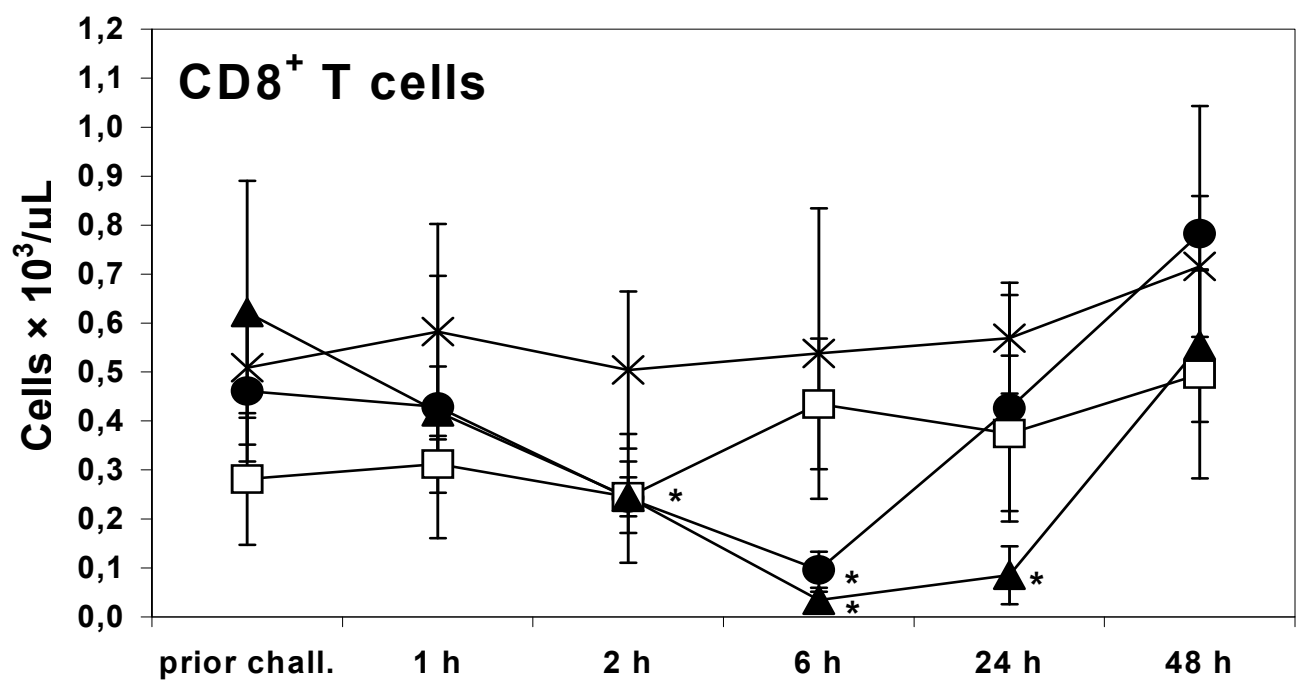

(e).

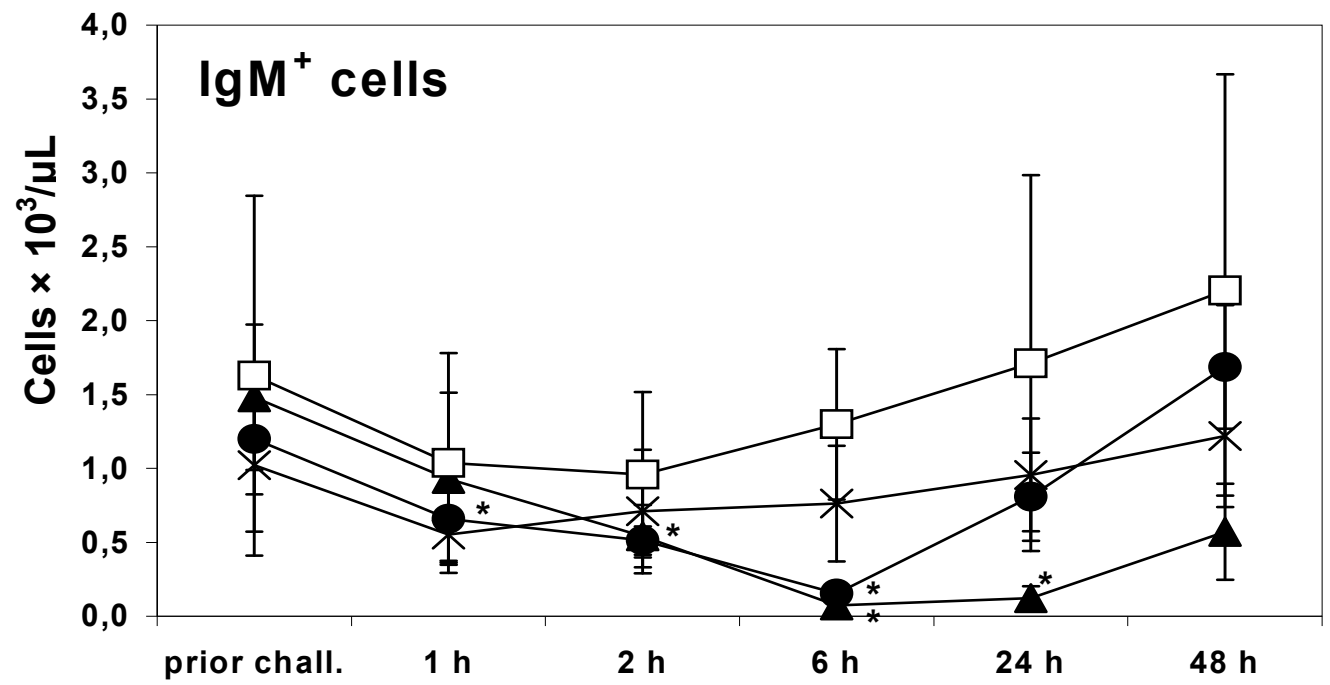


Figure 1. Cont.

(f).

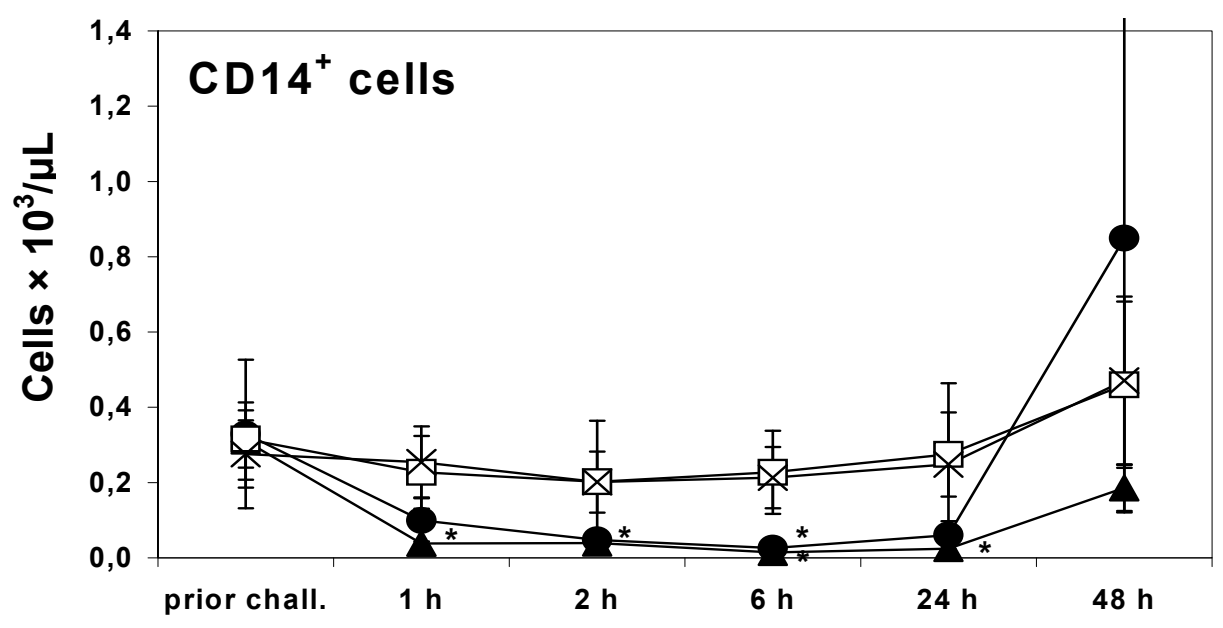

2.2. T cell activation by proliferation assays in human PBMCs can be detected after stimulation with wtTSST-1 and G31R but not with H135A

The mitogenic effects of TSST-1 and several mutants of TSST-1 have been studied in several species. Furthermore, TSST-1 and the mutants G31R and H135A have been compared in terms of their $\mathrm{T}$ cell activation by monitoring the percentage of $\mathrm{V} \beta 2^{+} \mathrm{CD} 25^{+}$expressing cells in flow cytometry studies [27]. Here, we compare the dose response of $\mathrm{T}$ cell activation by measuring the proliferative capacity of human PBMC. We found that G31R significantly stimulated the proliferation of $\mathrm{T}$ cells in a range from $10 \mu \mathrm{g} / \mathrm{mL}-1 \mathrm{ng} / \mathrm{mL}$ as compared to medium. This was lower than proliferation induced by TSST-1, whereas H135A was devoid of mitogenic capacity in the whole range (Figure 2).

Figure 2. $\mathrm{T}$ cell activation and proliferation of human PBMC is induced by G31R and TSST-1. No proliferation of human PBMC after stimulation with H135A. Human PBMC derived from healthy donors were cultured for 5 days in the presence of the indicated concentrations of TSST-1 $(n=4$, black bars), G31R $(n=6$, hatched bars $)$ and H135A $(\mathrm{n}=4$, open bars). Columns represent mean values $\pm \mathrm{SD}$ of dpm as a measure of $3 \mathrm{H}$-thymidine uptake of cells. As a positive control, PBMC were stimulated by PHA.

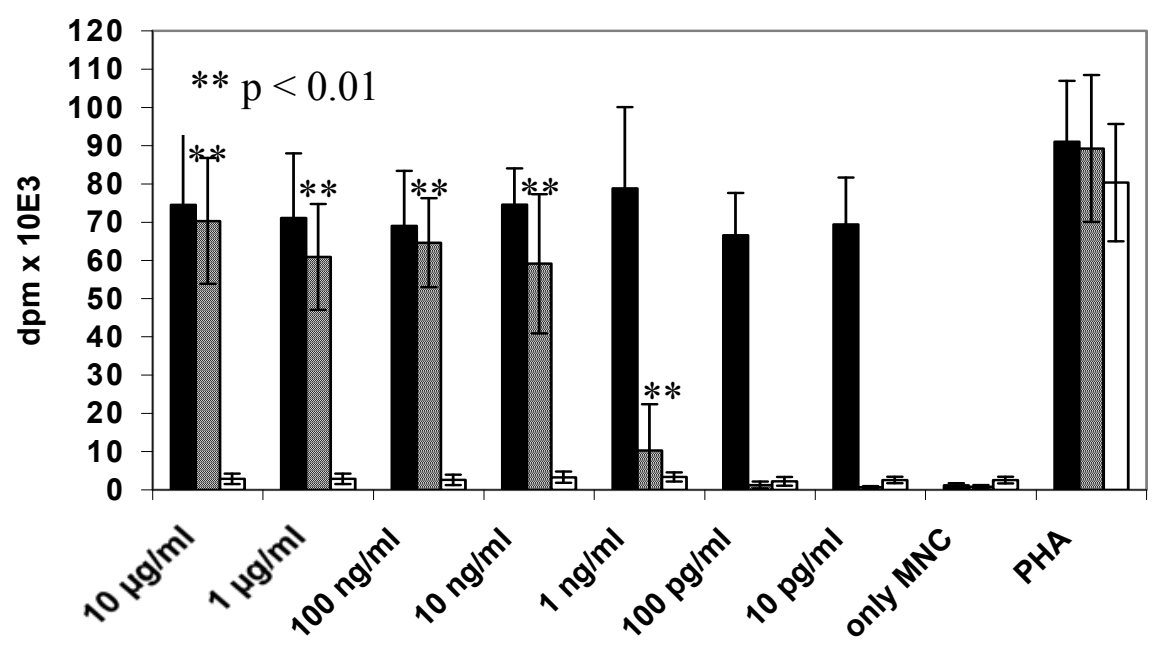


2.3. IL-2 expression is induced in the organs after administration of wtTSST-1 and G31R but not after administration of $\mathrm{H} 135 \mathrm{~A}$

Injection of G31R resulted in an induction of IL-2 gene expression in the spleen (Figure 3). The induction of IL-2 gene expression was similar after application of wtTSST-1. By contrast, no induction of IL-2 gene expression was noted in the spleen when H135A was given.

Figure 3. IL-2 gene activation in the spleen after administration of TSST-1 and G31R. Rabbits were challenged with G31R, wtTSST-1, and H135A for 4h and the spleen was extracted as described in Materials and Methods. IL-2 expression was determined via real time PCR and was related to the expression of the house-keeping gene GAPDH by dividing the IL-2 mRNA copy numbers through the mRNA copy numbers of GAPDH.

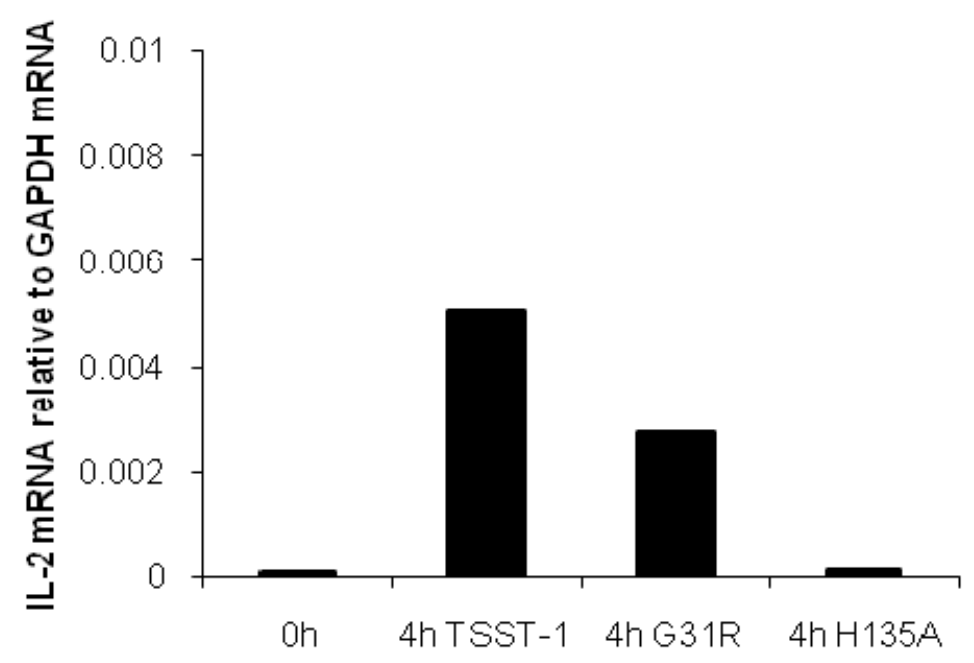

2.4. TSST-1 and G31R induce inflammatory cytokines in the organs

As previously shown [17], cytokine gene expression is significantly induced in the organs after application of TSST-1. Here we addressed the question whether the mutants of TSST-1 induced different cytokine profile compared to that of the wildtype.

Figure 4A shows the cytokine expression in the spleen after administration of G31R. We detected a cytokine expression pattern similar to that observed after application of TSST-1. IL-6 (black bars) was strongly induced (500-fold) and also IFN $\gamma$ gene expression (hatched bars) was significantly enhanced (50-fold). IL-1 $\beta$ (white bars) and TNF $\alpha$ (grey bars) were slightly increased (6-fold and 5-fold, respectively).

The induction levels after administration of TSST-1 were comparable (Figure 4B). IL-6 (black bar) was most strongly induced (400-fold) but also IFN $\gamma$ (hatched bar) was significantly induced (100-fold). Inductions of IL-1 $\beta$ (white bar; 24-fold) and TNF $\alpha$ (grey bar; 7-fold) were less. Induction of gene expression was also observed in other organs (liver, lung) but it was considerably less than in the spleen (data not shown).

By contrast, application of H135A did not significantly increase any cytokine expression (Figure 4c). 
Figure 4. (a-c) The expression of proinflammatory cytokines is induced in the spleens of rabbits after a challenge with G31R and wt TSST-1. Rabbits were challenged for $4 \mathrm{~h}$ and the expression of the proinflammatory cytokines was measured in the spleen by real time PCR. (a) G31R and (b) TSST-1 strongly increase the expression of IL-6 (black bars, $\mathbf{a})$ and IFN $\gamma$ (hatched bars, $\boldsymbol{z}$ ). Induction of IL-1 $\beta$ (white bars, $\square$ ) and TNF $\alpha$ (grey bars, $\square$ ) was weak (6-fold and 5-fold). (c) H135A did not cause an induction of cytokines.

(a).

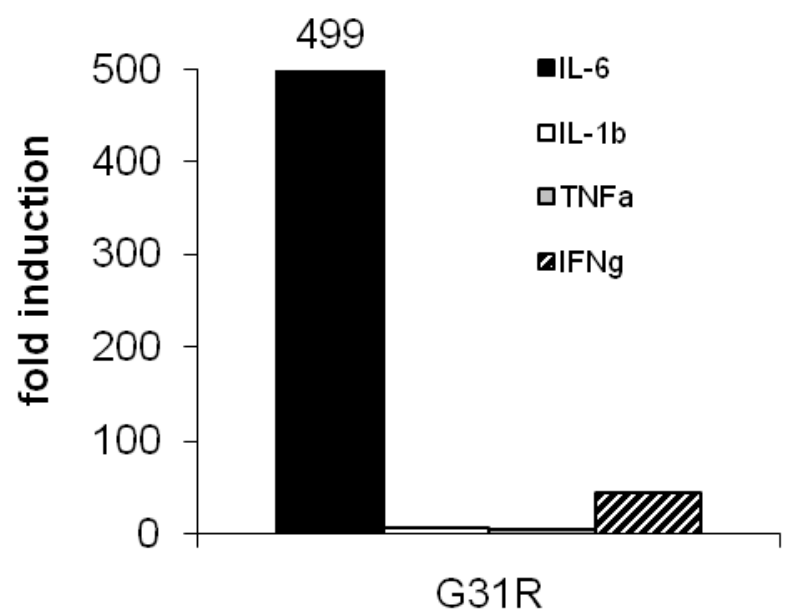

(b).

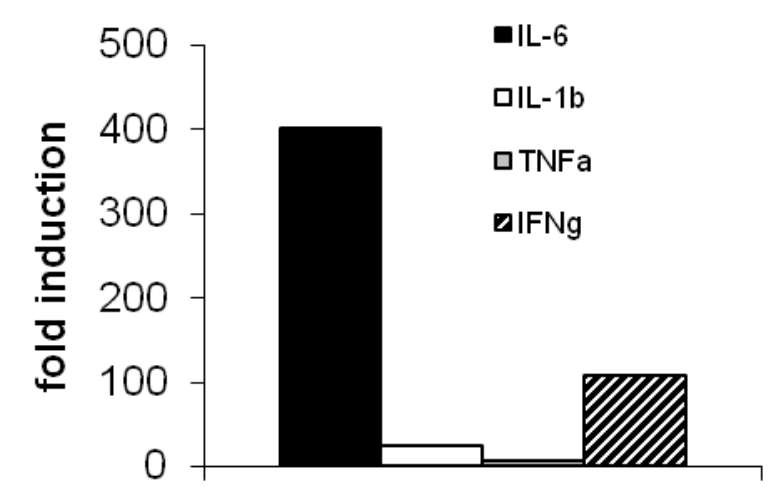

TSST-1

(c).

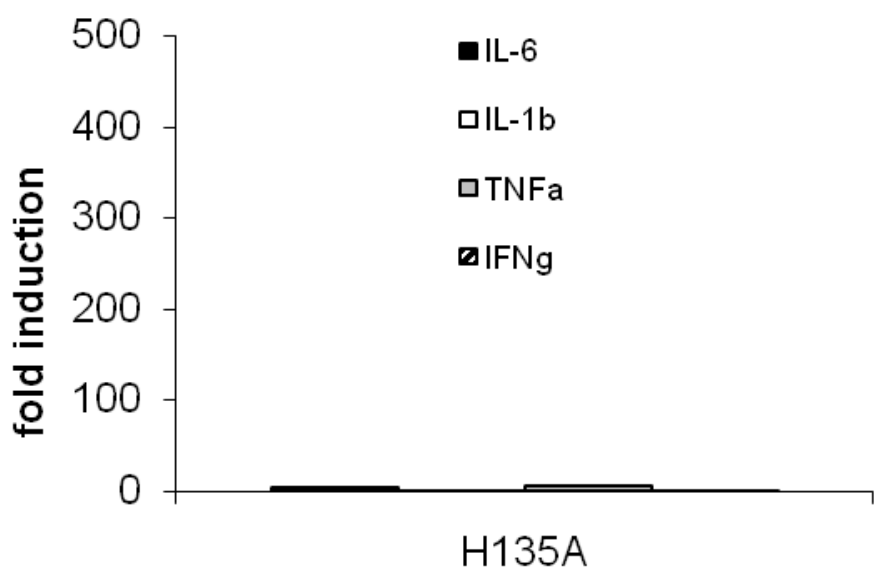

2.5. G31R- and H135A- pre-priming differ in the induction of the cytokine storm after LPS triggering

LPS administration after TSST-1 priming leads to a cytokine storm in the organs. Here we show that G31R + LPS (Figure 5A) led to a cytokine storm. IL-6 was induced 3113-fold, IFN $\gamma$ 871-fold, IL-1 $\beta$ and TNF $\alpha$ both 50-fold. These levels were comparable to those observed after TSST-1 + LPS treatment (Figure 5B). By contrast, H135A + LPS (Figure 5C) did not give rise to significant cytokine gene induction. The induction was slightly stronger than after application of LPS alone (Figure 5D). Table 1 summarizes the fold induction levels of the proinflammatory cytokines in the spleen. 
Figure 5. (a-d) Pre-priming with TSST-1 leads to a strong enhancement of LPS sensitivity and to a subsequent cytokine storm in the spleen. Rabbits were challenged for $4 \mathrm{~h}$ with wtTSST-1, G31R and H135A followed by administration of LPS for a further $2 \mathrm{~h}$. The expression of proinflammatory cytokines was quantified with real time PCR. (a) G31R + LPS and (b) TSST-1 + LPS induce an exorbitant expression of pro-inflammatory cytokines, particularly of IL-6 (black bars, $\boldsymbol{0}$ ) and IFN $\gamma$ (hatched bars, $\boldsymbol{\nabla}$ ). IL-1 $\beta$ (white bars, $\square$ ) and TNF $\alpha$ (grey bars, $\square$ ) were less induced. There was no induction of cytokines in rabbits treated with (c) H135A + LPS in comparison to (d) LPS-challenged animals.

(a).

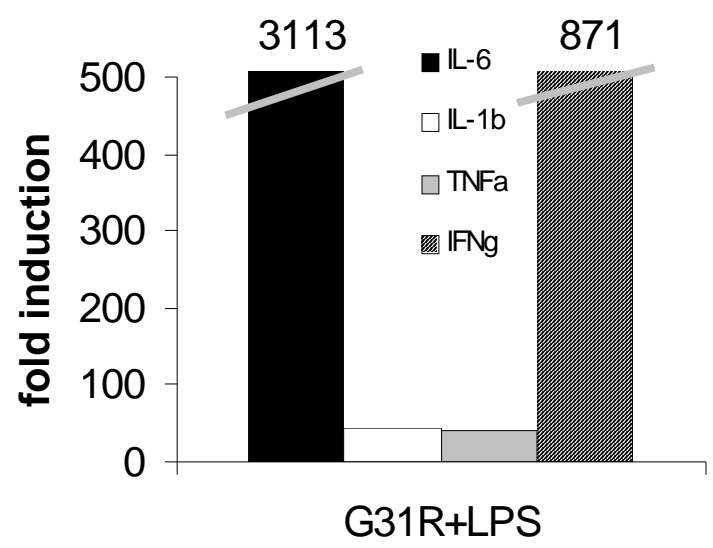

(c).

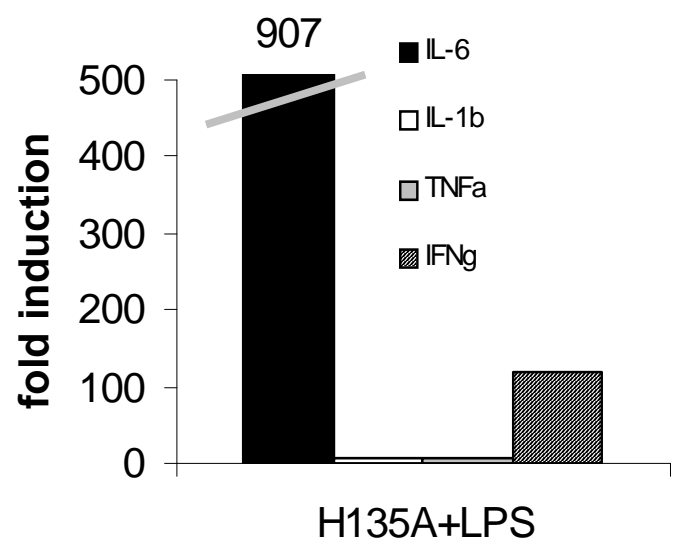

(b).

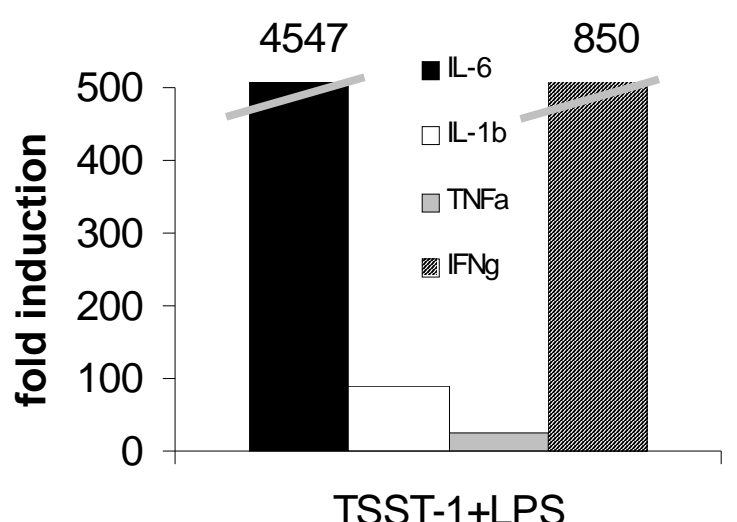

(d).

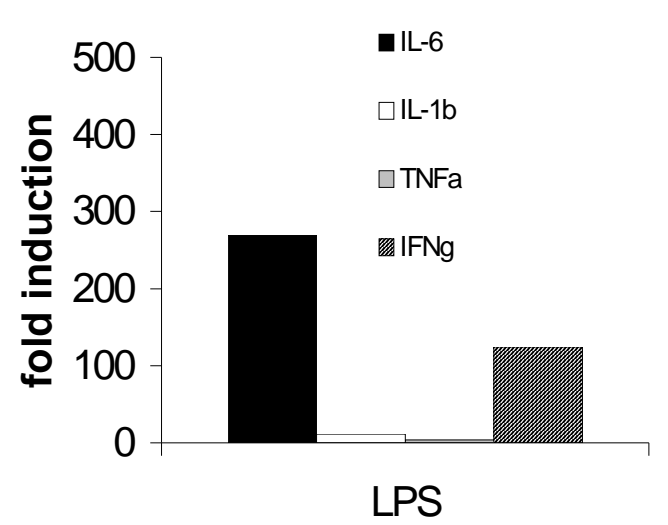

\subsection{Discussion}

There is general agreement that animal models available at present are sub-optimal for understanding the sequence of events in sepsis. Even though it is generally agreed upon that infection by one or several microbial agents is responsible for pathogenesis, the diagnosis of sepsis still greatly relies on clinical symptoms of inflammation and, in spite of greatly improved methodology in microbiology, the identification of an underlying infection, proven by the detection of bacteremia, is still lacking in $30-50 \%$ of cases.

Even though the amplification of endotoxins (LPS) of Gram-negative bacteria by exotoxins of Gram-positive bacteria (with characteristics of sAg) is clearly established, this notion has not been 
taken into consideration in animal models of sepsis. Extensive colonization of the population with Gram-positive bacteria and the relevance of the interrelation between colonizing and invasive infection in septic patients is well recognized [18].

Investigation in infants who died of SIDS (Sudden Infant Death Syndrome) revealed that these infants were significantly more often, more extensively double colonized with S. aureus [19] and E. coli [20]. We have raised the hypothesis that a similar mechanism may be operational in sepsis because of the frequent colonization with toxin-producing $S$. aureus and endotoxin-producing and releasing E. coli in the gut. Evidence of considerable contact with toxin-producing staph is provided by the fact that over $90 \%$ of adults have antibodies to at least one, but usually several, staph toxins. TSST-1 potentiates the activity of endogenous endotoxin by inhibiting clearance from the blood [21]. We applied the combined treatment of the staph exotoxins, e.g., TSST-1, and endotoxin of Gram-negative bacteria, e.g., LPS of E. coli, as our experimental model in order to delineate the cellular sequence of the events in this system.

The rabbit was selected as the species most appropriate for these studies because of its high sensitivity to staph sAg. Although most animal studies have been performed in mice, sensitivity of mice to these sAg is extremely low. Application of $200 \mu \mathrm{g} / \mathrm{kg}$ of TSST-1 followed by $400 \mu \mathrm{g} / \mathrm{kg}$ of LPS was needed to cause a fatality rate of $50 \%$ in mice, whereas $10 \mathrm{ng} / \mathrm{kg} \mathrm{TSST}-1$ and $10 \mu \mathrm{g} / \mathrm{kg} \mathrm{LPS}$ were required to bring about a fatality rate of $100 \%$ in rabbits [22]. Notably, lethality developed at approximately the same peak circulating level of TNFa in mice and rabbits showing that both species are equally sensitive to the lethal effects of circulating TNFa.

Furthermore, exposure to the toxin-producing bacteria and/or the toxin itself causes a disease in rabbits similar to human TSS. Therefore, as previously pointed out [17,23], the rabbit model has been preferred to answer questions regarding the pathophysiology of TSS.

In the rabbit model we started to analyze the interrelation between $\mathrm{T}$ cell activation and inflammation: assessing $\mathrm{T}$ cell activation by lymphocyte proliferation and IL-2 gene expression and inflammation by activation of the genes of proinflammatory cytokines (IL-6, TNF $\alpha$, IL-1 $\beta$ and IFN $\gamma$ ).

In a previous paper, analyzing the effect of TSST-1 in vivo in rabbits, we described that application of sAg leads to V $\beta$-unrestricted migration of MNC from the circulation [17]. Activated cells have been detected in organs, e.g., the spleen, the liver and the lung. The compartmentalization of the response after exposure to sAg is important but often neglected. Cytokines produced (early) in the organs, such as TNF $\alpha$ in the spleen [3,24], might not be detected in the periphery. Other authors described that lymphocytes leave the circulation in a $\mathrm{V} \beta$-dependent manner [25]. Thus, mechanisms of this extravasation are not well understood in this context. As the migrating cells (activated T cells, B cells, and cells of the monocyte macrophage lineage) all express MHC II on their surface, it was unclear whether direct interaction between sAg and these cells via MHC II would be sufficient to trigger the process. Leukopenia and lymphopenia were described after sAg challenge in different species and lymphopenia is also a frequent finding in patients with TSS and septic shock caused by S. aureus. Results of experiments with the mutant toxins clearly indicate that sAg-TCR interaction is a mandatory step for extravasation. The G31R mutant with the intact TCR binding site induced extravasation of lymphocytes comparable to TSST-1 (Figure 1). In contrast, the mutant H135A with intact MHC II binding, but defect in TCR interaction, had no effect (Figure 1). Our analysis of the mutants G31R and 
H135A confirmed the results of Kum et al. [9] describing that the mutant G31R induced significant $\mathrm{T}$ cell activation, albeit of lower magnitude than TSST-1 in human MNC.

Table 1. Fold induction levels of proinflammatory cytokines in the spleen after administration of sAg, LPS or the combination.

\begin{tabular}{|c|c|c|}
\hline Cytokine & Toxin & Fold induction \\
\hline IL-6 & TSST-1 & 401 \\
\hline IL-6 & G31R & 499 \\
\hline IL-6 & $\mathrm{H} 135 \mathrm{~A}$ & 3 \\
\hline IL-6 & TSST-1 + LPS & 4547 \\
\hline IL-6 & G31R + LPS & 3113 \\
\hline IL-6 & H135A + LPS & 907 \\
\hline IL-6 & LPS & 268 \\
\hline IFN $\gamma$ & TSST-1 & 107 \\
\hline $\mathrm{IFN} \gamma$ & G31R & 44 \\
\hline $\mathrm{IFN} \gamma$ & $\mathrm{H} 135 \mathrm{~A}$ & 0 \\
\hline $\mathrm{IFN} \gamma$ & TSST-1 + LPS & 850 \\
\hline $\mathrm{IFN} \gamma$ & G31R + LPS & 871 \\
\hline $\mathrm{IFN} \gamma$ & H135A + LPS & 120 \\
\hline IFN $\gamma$ & LPS & 124 \\
\hline IL-1 $\beta$ & TSST-1 & 24 \\
\hline IL-1 $\beta$ & G31R & 6 \\
\hline IL-1 $\beta$ & $\mathrm{H} 135 \mathrm{~A}$ & 0 \\
\hline IL-1 $\beta$ & TSST-1 + LPS & 90 \\
\hline IL-1 $\beta$ & G31R + LPS & 44 \\
\hline IL-1 $\beta$ & H135A + LPS & 5 \\
\hline IL-1 $\beta$ & LPS & 11 \\
\hline $\mathrm{TNF} \alpha$ & TSST-1 & 7 \\
\hline TNF $\alpha$ & G31R & 5 \\
\hline TNF $\alpha$ & $\mathrm{H} 135 \mathrm{~A}$ & 1 \\
\hline TNF $\alpha$ & TSST-1 + LPS & 26 \\
\hline TNF $\alpha$ & G31R + LPS & 39 \\
\hline TNF $\alpha$ & H135A + LPS & 7 \\
\hline TNF $\alpha$ & LPS & 4 \\
\hline
\end{tabular}

Cells activated by sAg migrate from the circulation to the organs, e.g., the spleen and the liver. IL-2 gene expression could be detected early after TSST-1 challenge mainly in the spleen of rabbits [17]. Similarly, T cells from the spleen were described to be the source of early TNF $\alpha$ in response to SEB in D-galactosamine-sensitized mice [3].

Here, we report induction of IL-2 gene expression in the spleen of rabbits treated with G31R and wtTSST-1 while no increased expression could be detected with H135A. These findings led us to ask the question whether T cell activation, i.e., IL-2 gene expression, is correlated with the amplification of 
the inflammatory response induced by LPS. To the best of our knowledge, there are no in vivo reports available describing that rabbits pre-treated with TSST-1 reacted with a cytokine storm in the organs when LPS was given later. Induction of proinflammatory cytokine genes, mainly IL-6 but also IFN $\gamma$, IL-1 $\beta$ and TNF $\alpha$, was higher than observed after treatment with either toxin alone. These proinflammatory cytokines are mainly produced by non- $T$ cells, mainly macrophages and dendritic cells. The results clearly indicate that the primary signal is given by T cells leading to activation of IL- 6 expression by macrophages and dendritic cells. It has been shown in mouse [15] in vivo and in human cells in vitro [26] that sAgs enhance the TLR4 expression on monocytes. We also observed a slight increase of TLR4 gene expression in rabbits and mice following administration of TSST-1 (unpublished results). This enhanced expression of TLR4 may be responsible for the augmented susceptibility to its ligand LPS.

Moreover, sAg may also modulate the interaction between staph and other entities of innate immunity, e.g., TLR2, which may be of importance in clearing staph infections.

The mutant H135A did not induce T cell proliferation or IL-2 gene expression. Thus, this mutant did not have the potential for $\mathrm{T}$ cell activation. This mutant did not induce extravasation of lymphocytes and monocytes, nor did it sensitize for the LPS-triggered cytokine burst, proving that T-cell activation is mandatory for these biological effects. Even though the combined effect of sAg and LPS has rarely been studied, and not in the same system, these results are in agreement with the report of Kum et al. [9] and differ from the studies of Roggiani et al. [16]. The reason for this difference could be explained by the different sAg applied (streptococcal versus staphylococcal) and by the different experimental setup. Other studies drew their conclusions from in vitro experiments [9] or from studies performed in mice [27] or rats [28].

\section{Experimental Section}

\subsection{Animals}

New Zealand white female rabbits $1.5-2 \mathrm{~kg}$ were purchased from Charles River Laboratories (Sulzfeld, Germany). Animals were kept in standard care facilities according to the guidelines of the Austrian Ministry for Science and Research and had free access to food (Altromin 2120 standard diet pellets; Marek Futtermittelwerke, Vienna, Austria) and water. The animal experiments had been approved and controlled by the Veterinary Department of the City of Vienna.

\subsection{Injection of the toxins}

$100 \mu \mathrm{g}$ of the wt TSST-1, G31R, H135A and $10 \mu \mathrm{g}$ of LPS were applied for time periods as indicated in the figures. The substances were dissolved in $1 \mathrm{~mL}$ of PBS, sterile filtered and injected as previously described [17]. For control experiments, PBS was either subcutaneously $(2 \times 0.5 \mathrm{~mL})$ or intravenously $(1 \times 1 \mathrm{~mL})$ administered.

\subsection{Organ extraction, RNA isolation and reverse transcription}

Organ extraction after anaesthesia of rabbits was performed at time points indicated in the figures and was extensively described in a previous report [17]. Organs were then homogenized using an 
Ultra-Turrax T8 homogenizator (IKA, Staufen, Germany) and RNA was extracted according to the protocol of the manufacturer. $900 \mathrm{ng}$ of RNA was reversely transcribed using the 2xRT Kit from Invitrogen (Invitrogen, Paisley, UK).

\subsection{Substances}

TSST-1, G31R and H135A were produced in our laboratory. Both the expression and purification of TSST-1, G31R and H135A are extensively described by Gampfer et al. [29]. All substances were tested for their biological activities in our laboratory and were proven to be endotoxin-free.

\subsection{Antibodies for flowcytometry analyses}

The murine unlabeled or conjugated mAbs recognizing the rabbit cell surface antigens CD4 (clone: KEN-4), CD8 (clone: 12C7), IgM (clone: NRBM) and CD14 (clone: Tsk4) were purchased from Serotec (Oxford, UK). The corresponding IgG1 and IgG2a negative control mAbs were obtained from BD Pharmingen (Becton Dickinson, San Jose, CA, USA).

\subsection{Immunofluorescence analyses}

Venous EDTA-whole blood samples drawn before and 1 h, 2 h, 6 h, 24 h and 48 h after injection were analyzed for their leukocyte and lymphocyte counts with the help of a Coulter counter machine (Beckman Coulter) and a hematology analyzer (Abbott Laboratories, Abbott park, IL, USA) followed by flow cytometry. Immunofluorescence analyses were performed as previously described [17]. In short, $100 \mu \mathrm{L}$ whole blood was incubated with mAbs specific for CD4, CD8, CD14, IgM or irrelevant isotype-matched mAbs. After incubation, cells were washed and binding of the primary mAb was visualized using rabbit $\mathrm{F}(\mathrm{ab}$ ')2 anti-mouse Ig-fluorescein isothiocyanate (FITC) (STAR9B; Serotec). Subsequently, cells were lysed, washed and analyzed on a FACS Calibur flow cytometer supported by the CELLQUEST software (Becton Dickinson). FACS-data allowed determining the percentage of granulocytes and mononuclear cells (MNC) within these whole blood samples by gating cells according to their size and granularity. Consequently, absolute granulocyte numbers were calculated. The knowledge of the calculated absolute MNC numbers, and the percentage of $\mathrm{CD}^{+}, \mathrm{CD}^{+}, \mathrm{IgM}^{+}$ and $\mathrm{CD} 14^{+}$cells within the MNC population, allowed determination of absolute cell numbers of these subpopulations within the whole blood samples.

\subsection{Lymphocyte proliferation assay}

Peripheral blood mononuclear cells (PBMC) were isolated from heparinized blood of healthy human adults using density gradient centrifugation with LymphoprepTM (Axis-Shield PoC, Oslo, Norway), as previously described [17]. In brief, cells $\left(1 \times 10^{5}\right.$ cells/well $)$ were cultured in 96-well flat-bottom tissue culture plates (Sarstedt, Newton, NC, USA) in complete medium consisting of RPMI 1640 medium (PAA laboratories, Pasching, Austria), 10\% FCS (HyClone, Logan, UT, USA), $2 \mathrm{mM}$ L-glutamine (Invitrogen, Paisley, UK), $100 \mathrm{U} / \mathrm{mL}$ penicillin, and $100 \mu \mathrm{g} / \mathrm{mL}$ streptomycin (Invitrogen). PBMC were stimulated in triplicate by rTSST-1, G31R and H135A used in final concentrations between $10 \mu \mathrm{g} / \mathrm{mL}$ and $10 \mathrm{pg} / \mathrm{mL}$. As a positive control, phytohaemagglutinin (PHA, 
Sigma-Aldrich, St. Louis, MO, USA) were used in the final dilution of 1:320. Stimulated cells were cultured for five days in a humidified atmosphere $\left(37{ }^{\circ} \mathrm{C}, 5 \% \mathrm{CO}_{2}\right)$. On day four, $0.5 \mu \mathrm{Ci} /$ well $3 \mathrm{H}$-thymidine (GE Healthcare, Chalfont St Giles, UK) was added and $18 \mathrm{~h}$ later cells were frozen and stored at $-20{ }^{\circ} \mathrm{C}$ until harvesting onto glass fiber filters. Incorporated radioactivity was determined on a MicroBeta Trilux 1450 scintillation counter (Wallac, Turku, Finland) and expressed as dpm.

\subsection{Primers}

Gene-specific oligonucleotide primers were designed by hand and by primer design Primer Express ${ }^{\circledR}$ v2.0 software from Applied Biosystems (Foster City, CA, USA). Where genomic sequence information of rabbit was not available, consensus sequences of the cytokine genes from human and mouse served for primer design. Primer pairs were synthesized at MWG Biotech (Heidelberg, Germany) and at Invitrogen.

\subsection{Preparation of external cDNA standards}

CDNA standards were prepared as previously described [17] and served for absolute quantification of the target samples.

\subsection{QRT-PCR and quantification}

Quantitative Real time PCR has been extensively described [17]. In short, cDNA from samples and standards were simultaneously amplified on the same plate using an ABI Prism 7700 (Applied Biosystems, Foster City, CA, USA) using the SYBR Green Super Mix from Invitrogen with a ROX reference dye. At the end of the amplification, a melting curve analysis was performed.

The number of target cDNA copy numbers in the cellular samples was then calculated by creating a standard curve where the cycles at threshold (CT) were plotted against the logarithmic values of the cDNA standard copy number. GAPDH served as an internal standard. Fold induction of gene expression was assessed from values normalized for the expression of GAPDH and then related to the mean values derived from the spleen of three unchallenged rabbits.

\subsection{Statistical analyses}

Paired t-test has been applied to calculate the significance of the decrease between pre- and post-application values of WBC, lymphocytes and lymphocyte subsets. A decrease was considered to be significant at a $p$ value $\leq 0.05$ and is marked with an asterix.

Students' t-test has been applied to evaluate the significance $(\mathrm{p} \leq 0.01)$ in proliferation experiments.

\section{Conclusions}

In conclusion, we prove in vivo that following exposure to sAg, $\mathrm{T}$ cell activation is the mandatory first step for the inflammatory/toxic effects studied. The most pronounced cause of toxicity is the cytokine storm in sepsis and it has been suggested that the cytokine storm is mainly responsible for toxicity. The majority of cells involved in the production of proinflammatory cytokines are non-T cells, such as B cells and cells of the monocyte/macrophage lineage. Our findings demonstrate 
the primary role of $\mathrm{T}$ cells in activation and/or triggering of these non- $\mathrm{T}$ cell populations. $\mathrm{T}$ cells have been shown to modulate the inflammatory reaction. The understanding of the mechanism of $\mathrm{T}$ cell modulation of the inflammatory response in this context is of pivotal importance and is presently under investigation in our lab.

\section{Acknowledgements}

The authors are grateful to Helga Bergmeister for her support in the performance of the experimental studies, Elisabeth Jägersberger for technical assistance and Claire Bullivant for preparation of the manuscript.

\section{References}

1. Dinges, M.M.; Orwin, P.M.; Schlievert, P.M. Exotoxins of Staphylococcus aureus. Clin. Microbiol. Rev. 2000, 13, 16-34.

2. Marrack, P.; Blackman, M.; Kushnir, E.; Kappler, J. The toxicity of staphylococcal enterotoxin B in mice is mediated by T cells. J. Exp. Med. 1990, 171, 455-464.

3. Faulkner, L.; Cooper, A.; Fantino, C.; Altman, D.M.; Sriskandan, S. The mechanism of superantigen-mediated toxic shock: not a simple Th1 cytokine storm. J. Immunol. 2005, 175, 6870-6877.

4. Sriskandan, S.; Faulkner, L.; Hopkins, P. Streptococcus pyogenes: Insight into the function of the streptococcal superantigens. Int. J. Biochem. Cell Biol. 2007, 39, 12-19.

5. Sriskandan, S.; Unnikrishnan, M.; Krausz, T.; Dewchand, H.; van Norden, S.; Cohen, J.; Altmann, D.M. Enhanced susceptibility to superantigen-associated streptococcal sepsis in human leukocyte antigen-DQ transgenic mice. J. Infect. Dis. 2001, 184, 166-173.

6. Welcher, B.C.; Carra, J.H.; DaSilva, L.; Hanson, J.; David, C.S.; Aman, M.J.; Bavari, S. Lethal shock induced by streptococcal pyrogenic exotoxin A in mice transgenic for human leukocyte antigen-DQ8 and human CD4 receptors: Implications for development of vaccines and therapeutics. J. Infect. Dis. 2002, 186, 501-510.

7. Bonventre, P.F.; Heeg, H.; Edwards, C.K.; Cullen, C.M. A mutation at histidine residue 135 of TSST-1 yields an immunogenic protein with minimal toxicity. Infect. Immun. 1995, 63, 509-515.

8. Kum, W.W.; Wood, J.A.; Chow, A.W. A mutation at glycine residue 31 of toxic shock syndrome toxin-1 defindes a functional site critical for major histocompatibility complex class II binding and superantigenic activity. J. Infect. Dis. 1996, 174, 1261-1270.

9. Kum, W.S.; Cameron, S.B.; Hung, R.W.Y.; Kalyan, S.; Chow, A.W. Temporal sequence and kinetics of proinflammatory and anti-inflammatory cytokine secretion induced by toxic shock syndrome toxin 1 in human peripheral bloodmononuclear cells. Infect. Immun. 2001, 69, 7544-7549.

10. Dong-Liang, H.; Omoe, K.; Sasaki, S.; Sashinami, H.; Sakuraba, H.; Yokomizo, Y.; Shinagawa, K.; Nakane, A. Vaccination with nontoxic mutant toxic shock syndrome toxin 1 protects against Staphylococcus aureus infection. J. Infect. Dis. 2003, 188, 743-752. 
11. Llewelyn, M.; Sriskandan, S.; Peakman, M.; Ambrozak, D.R.; Douek, D.C.; Kwok, W.W.; Cohen, J.; Altmann, D.M. HLA Class II polymorphisms determine responses to bacterial superantigens. J. Immunol. 2004, 172, 1719-1726.

12. Roggiani, M.; Stoehr, B.; Leonard, A.; Schlievert, P.M. Analysis of toxicity of streptococcal pyrogenic exotoxin A mutants. Infect. Immun. 1997, 65, 2868-2875.

13. Dinges, M.M.; Gregerson, D.S.; Tripp, T.J.; McCormick, J.K.; Schlievert, P.M. Effects of total body irradiation and cyclosporin A on the lethality of toxic shock syndrome toxin-1 in a rabbit model of toxic shock syndrome. J. Infect. Dis. 2003, 188, 1142-1145.

14. Schlievert, P.M. Enhancement of host susceptibility to lethal endotoxin shock by staphylococcal pyrogenic exotoxin type C. Infect. Immun. 1982, 36, 123-128.

15. Rossi, R.J.; Muralimohan, G.; Maxwell, J.R.; Vella, A.T. Staphylococcal enterotoxins condition cells of the innate immune system for Toll-like receptor 4 stimulation. Int. Immunol. 2004, 16, 1751-1760.

16. Beno, D.W.; Uhing, M.R.; Goto, M.; Chen, Y.; Jiyamapa-Serna, V.A.; Kimura, R.E. Chronic staphylococcal enterotoxin B and LPS induce a bimodal pattern of hepatic dysfunction and injury. Crit. Care Med. 2003, 31, 1154-1159.

17. Waclavicek, M.; Stich, N.; Rappan, I.; Bergmeister, H.; Eibl, M.M. Analysis of the early response to TSST-1 reveals V $\beta$-unrestricted extravasation, compartmentalization of the response, and unresponsiveness but not anergy to TSST-1. J. Leukoc. Biol. 2009, 85, 44-54.

18. Vincent, J.L.; Sakr, Y.; Sprung, C.L.; Ranieri, V.M.; Reinhart, K.; Gerlach, H.; Moreno, R.; Carlet, J.; Le Gall, J.R.; Payen, D. Sepsis in European intensive care units: Results of the SOAP study. Crit. Care Med. 2006, 34, 344-353.

19. Blackwell, C.C.; Mackenzie, D.A.C.; James, V.S.; Elton, R.A.; Zorgani, A.A.; Weir, D.M.; Busuttil, A. Toxigenic bacteria and sudden infant death syndrome (SIDS): Nasopharyngeal flora during the first year of life. FEMS Immunol. Med. Microbiol. 1999, 25, 51-58.

20. Oppenheim, B.A.; Barclay, G.R.; Morris, J.; Knox, F.; Barson, A.; Drucker, D.B.; Crawley, B.A.; Morris, J.A. Antibodies to endotoxin core in sudden infant death syndrome. Arch. Dis. Child. 1994, 70, 95-98.

21. Schlievert, P.M. Alteration of immune function by staphylococcal pyrogenic exotoxin type C: Possible role in toxic-shock syndrome. J. Infect. Dis. 1983, 147, 391-398.

22. Dinges, M.M.; Schlievert, P.M. Comparative analysis of lipopolysaccharide-induced tumor necrosis factor alpha activity in serum and lethality in mice and rabbits pretreated with the staphylococcal superantigen toxic shock syndrome toxin 1. Infect. Immun. 2001, 69, 7169-7172.

23. Parsonnet, J.; Gillis, Z.A.; Richter, A.G.; Pier, G.B. A rabbit model of toxic shock syndrome that uses a constant, subcutaneous infusion of toxic shock syndrome toxin 1. Infect. Immun. 1987, 55, 1070-1076.

24. Huston, J.M.; Ochani, M.; Rosas-Ballina, M.; Liao, H.; Ochani, K.; Pavlov, V.A. Splenectomy inactivates the cholinergic antiinflammatory pathway during lethal endotoxaemia and polymicrobial sepsis. J. Exp. Med. 2006, 203, 1623-1628.

25. Rellahan, B.L.; Jones, L.A.; Kruisbeek, A.M.; Fry, A.M.; Matis, L.A. In vivo induction of anergy in peripheral V $\beta 8^{+} \mathrm{T}$ cells by Staphylococcal enterotoxin B. J. Exp. Med. 1990, 172, 1091-1100. 
26. Hopkins, P.A.; Fraser, J.D.; Pridmore, A.C.; Russell, H.H.; Read, R.C.; Sriskandan, S. Superantigen recognition by HLA class II on monocytes up-regulates toll-like receptor 4 and enhances proinflammatory responses to endotoxin. Blood 2005, 105, 3655-3662.

27. Blank, C.; Luz, A.; Bendigs, S.; Erdmann, A.; Wagner, H.; Heeg, K. Superantigen and endotoxin synergize in the induction of lethal shock. Eur. J. Immunol. 1997, 27, 825-833.

28. Beno, D.W.; Uhing, M.R.; Goto, M.; Chen, Y.; Jiyamapa-Serna, V.A; Kimura, R.E. Chronic Staphylococcal enterotoxin B and lipopolysaccharide induce a bimodal pattern of hepatic dysfunction and injury. Crit. Care Med. 2003, 31, 1285-1286.

29. Gampfer, J.; Thon, V.; Gulle, H.; Wolf, H.M.; Eibl, M.M. Double mutant and formaldehyde inactivated TSST-1 as vaccine candidates for TSST-1-induced toxic shock syndrome. Vaccine 2002, 20, 1354-1364.

(C) 2010 by the authors; licensee MDPI, Basel, Switzerland. This article is an open access article distributed under the terms and conditions of the Creative Commons Attribution license (http://creativecommons.org/licenses/by/3.0/). 